\title{
Evaluation of MODIS albedo product (MCD43A) over grassland, agriculture and forest surface types during dormant and snow-covered periods
}

\author{
Zhuosen Wang ${ }^{\text {a,* }}$, Crystal B. Schaaf a, Alan H. Strahler ${ }^{\text {b }}$, Mark J. Chopping ${ }^{c}$, Miguel O. Román ${ }^{\text {, }}$, Yanmin Shuai ${ }^{\text {e,f }}$, \\ Curtis E. Woodcock ${ }^{b}$, David Y. Hollinger ${ }^{g}$, David R. Fitzjarrald ${ }^{\text {h }}$
}

¿ Environmental, Earth and Ocean Sciences Department, University of Massachusetts Boston, Boston, MA USA

th Center for Remote Sensing Department of Geography and Environment, Boston University, Boston, MA, USA

"Department of Earih and Envirormental Studies, Montclair State Umiversity, Montclair, NJ. USM

- Terrestrial Information Systems Laboratory (Code 619), NASA Gaddand Space Flight Center, Greenbelt, MD, USA

'Earth Resources Technology Inc. Laurel, MD. USA

' NASA Coddard Space Flight Center, Greenbelt, MD, USA

s USDA Forest Service Northem Research Station. Durham, NH, USA

" Amospheric Saiences Research Center, Umiversity at Albarty, SUNY, Albamy, NY, USA

\section{ARTICLE I NFO}

\section{Article history:}

Received 25 October 2012

Received in revised form 14 August 2013

Aocepted 17 August 2013

Available online 19 September 2013

\section{Keywords:}

MODIS standard and daily albedo producr

Snow albedo

Forest

Grassland

Spatial representativeness

\begin{abstract}
A B S T R A C T
This study assesses the Moderate-resolution Imaging Spectroradiometer (MODIS) BRDF/albedo 8 day standard product and products from the daily Direct Broadcast BRDF/albedo algorithm, and shows that these products agree well with ground-based albedo measurements during the more difficult periods of vegetation dormancy and snow cover. Cropland, grassland, deciduous and coniferous forests are considered. Using an integrated validation strategy, analyses of the representativeness of the surface heterogeneity under both dormant and snow-covered situations are performed to decide whether direct comparisons between ground measurements and 500 - $\mathrm{m}$ satellite observations can be made or whether finer spatial resolution airborne or spacebome data are required to scale the results at each location. Landsat Enhanced Thematic Mapper Plus (ETM+) data are used to generate finer scale representations of albedo at each location to fully link ground data with satellite data. In general, results indicate the root mean square errors (RMSEs) are less than 0.030 over spatially representative sites of agriculture/grassland during the dormant periods and less than 0.050 during the snow-covered periods for MCD43A albedo products. For forest, the RMSEs are less than 0.020 during the dormant period and 0.025 during the snow-covered periods. However, a daily retrieval strategy is necessary to capture ephemeral snow events or rapidly changing situations such as the spring snow melt.
\end{abstract}

(c) 2013 Elsevier inc. All rights reserved.

\section{Introduction}

Surface albedo, defined as the ratio of the total (hemispheric) rellected solar radiation flux to the incident flux upon the surface, quantifies the radiation interaction between the atmosphere and the land surface. It plays a crucial role in land surface climate and biosphere models (Dickinson \& Hanson, 1984; Dirmeyer \& Shukla, 1994; Lofgren, 1995). Carbon-only accounting approaches which ignore the albedo impacts of forests can significantly overestimate the climatic benefit of offsets (Thompson, Adams, \& Johnson, 2009). As a key land physical parameter controlling the surface radiation energy budget, an absolute accuracy of $0.02-0.05$ is required by climate models for global surface albedo (Dickinson, 1983, 1995; Dickinson et al, 2008; Henderson-Sellers \& Wilson, 1983).

\footnotetext{
- Corresponding author. Tel: + 16172875029.

E-mail addrexc: wangzhuosenegmail.com (2 Wang).
}

The surface reflectivity changes significantly with the appearance of snow. Snow also alters the exchange of moisture between the surface and the atmosphere especially during the snowmelt period (Marshall, Roads, \& Glatzmaier, 1994). The snow albedo contributes a strong positive feedback in surface modeling studies (Betts \& Ball, 1997; Bonan, Chapin, \& Thompson, 1995; Gardner \& Sharp, 2010; Koltzow, 2007; Li, Sun, Wang, \& Liu, 2009; Molders, Luijting, \& Sassen, 2008; Pedersen, Godtliebsen, \& Roesch, 2008; Pedersen, Roeckner, Luthje, \& Winther. 2009, Qu \& Hall, 2006; Rutter et al., 2009: Thomas \& Rowntree, 1992; Viterbo \& Betts, 1999; Wyser et al., 2007). The albedo at local solar noon for snow-covered forests is usually less than 0.3 in the shortwave, but it can reach 0.57 or higher for snow-covered grassland and barren locations (lin et al., 2002).

The Moderate-resolution Imaging Spectroradiometer (MODIS) BRDF/albedo products (Schaaf, Wang, \& Strahler, 2011a, Schaaf et aL., 2002,2008 ) have been available since 2000 and provide high quality surface reflectance anisotropy retrievals over a variety of land surface 
types (Jin et al, 2003b; Ling et al., 2002; Liu et al., 2009; Román et al. 2009, 2010). The Bidinetional Reflectance Distribution Function (BRDF) models and shapes (Gao, Schaal, Strahler, Jin, \& Li, 2003; Hil, Awerill. Jian, Schaar, \& Armston, 2008) are also irxreasingly being usexl to provide information about the surface vegetation structure and the albedo quantities have been embraced by the global climate modeling and numerical assimilation communities (Dickinson et at. 2008; Fang et al., 2007: Lawrence \& Chase, 2007; Morcrette, Barker, Cole, Lacano, \& Pincus, 2008: Myhre, Kvalevag. \& Schaaf, 2005. Oleson et al, 2003; Roesch, Schalf, \& Gao, 2004; Tian et al., 2004: Wei et al, 2001; Zhou et al. 2003).

Although reported on a $500 \mathrm{~m}$ grid, the MODIS BRDF/alledo products are usually retrieved utilizing observations from a larger area depending on the view angles. The fooxprint of observations increases with the increase in the scanning angle (Tan et al., 2006; Wolfe. Roy, \& Vermote, 1998). Observations are weighed by angular comerage before the retrieval but it must still be acknowledged that the $500 \mathrm{~m}$ gridded product actually represents information from a larger area.

A number of studlies have validated the MODIS albedo product by a direct "point-to-pixel" comparison (Chen, Liang. Wang. Kim, \& Martontriik 2008: Liu et al., 2009; Salomon, Sxthaar, Strahler, Cak, \& Jin, 2006; Wang et al, 2004) with the assumption that both the tower and satellite albedo roughly sample the same spatial domain. However, ground measurements from tower usually only cover a limited area, which is muxh smaller than the MODIS spatial resolution. An important difficulty encountered whenever attempts are made to compare satellite-retrieved albedo values to tower-measured albedo data is that the footprint of the ground measurement is not always representative of the greater satellite footprint. This is particularly true of rapidly changing surface conditions during senescence, green-up, and varying periods of snow cover. Assessments of spatial representativeness using Landsat data can provicle an estimate of the general ability of the satellite retrievals to capture the tower measurements (Roman et al., 2009, 2010). However, corslitions can change so rapidly during dormancy and eplemeral snow events that such assessments must be reconsidered frequently foc each situation.

Initial investigations with "point-to-pixel" comparisons at the Ameriflux Canadian University of Califomia-Irvine (UCl) bum forest sites in Canada suggest that the MODIS winter values were ustally lower than the tower values (Román et al., 2009). However these locations represent field sites with high spatial heterogeneity during winter periods. To consider the spatial scaling effect, finer spatial resolution Landsat Enlanced Thematic Mapper Plus (ETM +) data have been usually used to validate MODIS BRDF/albedo products (Fang, Liang. Chen, Watthall, \& Daughtry, 2004; Jin et al, 2003b; lieng et al, 2002; Susaki, Yasuoka, Kajiwara, Honda. \& Hara, 2007). Barnsley et al. (2000) and Lexht, Hyman, et al (2000) usexl Landsea data to analyze the spatial scaling effect on the albedo of a semi-desert environment prior to the launch of MODIS. It must be noted however that most of these studies have assumed a Lambertian surface to estimate Landsat albedo although jin et al. (2003b) calculated a Landsat albedo by applying the ratio of the MODIS hemispherical albedo at local solar noon to the directional surface reflectance at the Landsat observing geometry.

While the MODIS BRDF/aibedo products have been evaluated during the growing season for a number of vegetated land cowers with high $\mathrm{x}$ curacy (Disney, Lewis, Thackrah, Quaife, \& Bamsley, 2004; Jin et al. 20033, 2003b; Knobelspiesse, Caims, Schmid, Romain, \& Scthaaf, 2008; liang et al. 2002: Liu et al. 2009; Lyons, Jin, \& Randerson, 2008: Rpesch et al., 2004; Romnín et al., 2009, 2010; Salomon et al., 2006; Samain et al, 2008: Shuai, Schaaf, Strahler, Liu, \& Jiaa, 2008: Stone. Anderson, Shettle, Andrews, \& Loukadtine, 2008; Susaki ex al., 2007; Wang, Barlage, Zeng. Dickinson, \& Schaar, 2005; Wang et al, 2004). the assessment of the results during domant and snow-covered seasoos (Romkn et al., 2009. 2010: Schaaf, Liu, Gao, \& Srahier, 2011b; Wang et al, 2012) has only just begun.
The spatial patterns of albedo will change seasonally if the surface is comprised of different land types, This is especially true during dormant periods (when vegetation is not photosynthetically active and leaves are either brown and/or wery lew). Jin et al (2002) analyad the effect of snow ower different land covers and sbowed that snow caused high heterogeneity in the surface albedo making valiklation more difficult. Therefore, differences between the tower measurements and MODiS albedo should be expected and any evaluation of the MODIS BRDF/allecto products over dormant seasons, both snow-covered and snow-free. needs to pay particular attention to spatial scaling effects

For agricultural and temperate grassland areas, the ground is often cowered by dense uniform vegetation during the growing season. Thus, the surface is relative homogenous and ground measurements match well with MODIS products (Chen et at, 2008; jin et al., 2003b; liang et al., 2002; liu et al., 2009; Román et al., 2009, 2010; Susaki et al, 2007). However, these surfaces are often considerably more hererogeneous during dorinant or partly snow-covered periods Jin et al (2003b) and Chen et al. (2008) showed that there are relatively large differences between ground albedos and MODIS albedo produxts during these seasons.

Modeling and monitoring the albedo of forests during the snowconered periods can be difficult. $A$ snow-covered forest in winter is maxle up an upper layer of dark leaves and branches and a lawer layer of bright snow on the forest floor. Because of the upper foliage in dense evergreen forests, the reflected photons from the snow surdace have difficultikes escaping the forest canopy espexially under high zenith viewing angles; moreover, a large fraction of the understory may be shaded in winter scenes, owing to the higher solar zenith angles. However, the reflectance from deciduous forests, where snow information is more visible through a canopy of bare branches, is relatively high. The density of the canopy can also affect whether a pixel is designated as snow-covered or snow-free.

This study aims to assess the accuracy of MODIS albedo products by comparison with grourd messurements after establishing the spatial representativeness of vegetated surfaces during, dormant and snowcovered situations. Section 2 describes both the ground measurements and MODIS albedo proxducts and Sextion 3 outlines the assessment strategy. In Section 4, we compare the ground measurements to MODIS albedos and Landsat albetos where appropriate and discuss the overall accuracy of MODDS products during the domant and snow-covered seasons.

\section{Datasets}

\subsection{Ground measurements}

The primary validation sites used for the MODAS Albedo product bave historically been the Surface Radiation Budget Network (SURFRAD) sites (Augustine. Deluisi, \& Long. 2000) which are maintained in the United states by NOAA as part of the Baseline Surface Radiation Network (BSRN) (Ohmura et al_ 1998). The World Climate Reswath Programme (WCRP) Radiative Fluxes Working Group initiated the BSRN to support the research projects of the WCRP and other scientific programs. These seven SURFRAD sites (Fort Peck, MT, Sioux Falls, SD, Fem State, PA Bondville, II, Table Mountain, CD. Goodwin Creck, MS and Desert Rock NV) (Tabie 1] are used again in this study. In addition to the seven SURFRAD sites, the Boukler, $C O$ site is also ancher BSRN site close to the Table Mountain site that utilizes pyranometers mounted on a $300 \mathrm{~m}$ tawer. These eight sites provide the highest quality intercalilxated albexto measurements.

Three additional sites of New England forests from the Amerifiux network are also used in this study. Ameriflux was established by the Department of Energy (DOE) in 1996 to provide continuous observations of excasystem level exchanges of $\mathrm{CO}_{2}$, water, and energy, induding, surface albedo (Law et al, 2002; Running et al., 1999). 
TaNe 1

SURFRAD, SSRN, and Rmeriflux ground sites.

\begin{tabular}{|c|c|c|c|c|c|c|}
\hline Station name & Labitude/longirude & Jower height/footprint (m) & State & Land cover & Moots tile & Network \\
\hline Boulder & $4005 / 105.01$ & $300 / 378825$ & Colorado & Grassland & HOSVO4 & BSTN \\
\hline Fort Pock & $4831 / 105.10$ & $10 / 126.28$ & Montans & Grassland & H11V04 & SIRFRAD \\
\hline Goodwin Creek & $3425 t-8937$ & $10 / 12628$ & Mussissippi & Crassland & H10V05 & SUKIRAD \\
\hline Siouk Falls & $4373 / 9652$ & $10 / 126.28$ & South Dakota & Grassland & H11V04 & SURFRAD \\
\hline Table Moutcais & $10 / 2528$ & Colcrado & Grassland & Hogvon & SUKFXAD & \\
\hline \multicolumn{7}{|l|}{$40.13 /$} \\
\hline Desert Rock & 366211602 & $10 / 2628$ & Nevada & Desert, sperse grass & HсвиDG & SURFRAD \\
\hline Eondville & $4005, \quad 58.37$ & $10 / 22628$ & Minois & Agriculfute & H1tVI & SUKIKAD \\
\hline Peon State & 407217793 & $10 / 2628$ & Pennsylvania & Agriculture & HI2V04 & SURFRAD \\
\hline Mavand EMS & $42558 /=72.172$ & 309666 & Massachusetts & Mixed forest & Н12V04 & Amerifinx \\
\hline Howland Larch & $45.216 ! \quad 68.709$ & $30 / 366$ & Maine & Beribuos needlelear forest & H13V04 & Ameriflux \\
\hline Howland West & $45.2091 \quad 68.747$ & $30 / 366$ & Maìe & Evergreen mecdleleaf forest & H13v04 & Ameriflux \\
\hline
\end{tabular}

Total dowmward and upward radiation $(0.28-3.0 \mathrm{am})$ is measured by Eppley pyranometers mounted on the $10 \mathrm{~m}$ towers at the SURFRAD sites while the Boulder site utilizes a $300 \mathrm{~m}$ tower. Normal Incidence Pyranometers and shaded pyranometers are used to measure the direct normal and diffuse shortwave fluxes (Augustine et al, 2000). The instruments are ventilated and heated during the winter so that there is a great deal of confidence in the winter measurements as well as the growing season ones. Kipp and Zonen albedometers in the shortwave $(03-28 \mathrm{~cm})$ are used to measure albedo at Ameriflux sites. These albedometers are mounted on $30 \mathrm{~m}$ towers and not routinely beated and ventilated, therefore the data are not considered as reliable during snow precipitation periods. Ground albedo is calculated by the ratio of upwelling radiation and downwelling radiation during the local mid-day time. The footprints of $10 \mathrm{~m}, 30 \mathrm{~m}$, and $300 \mathrm{~m}$ towers are estimated to be about $126 \mathrm{~m}, 366 \mathrm{~m}$ and $3788 \mathrm{~m}$ in diameter respectively.

\section{$f \cap 2 \mathrm{H} \tan \mathrm{HRON}$}

Where $f$ is the circular footprint of ground tower measurements, $H[\mathrm{~m}]$ is the tower beight, and HFOV [degrees] is its half of field of view. HFOV is $81^{\circ}$ (Michaisky, Harrison, \& Berkheiser, 1995).

The Bondville SURFRAD site is located southwest of Champaign. Illinois, in an agricultural region (Fig. 1). This site represents a mixture of crops and drainage ditches which are maintained with a variety of harvesting and fallowing practices. It is quite heterogeneous at the MODIS scale (Liu et al, 2009; Salomon et al, 2006). The Sioux Falls SURFRAD site is located on the grounds of the Earth Resources Observation and Science (EROS) Data Center, South Dakota, and is covered by grass. The Goodwin Creek site, west of Oxford, Mississippi, is located on rural pasture land surrounded by deciduous trees. The Penn State University (PSU) SURFRAD site is located on the grounds of PSU's agricultural research farm about 6 miles southwest of State College, Pennsylvania and is in a broad Appalachian valley between the Tussey and Bald Eagle Ridges. The Fort Peck SURFRAD station is bcated on the fort Peck Tribes Reservation in Montana. This site is dominated by native grasses. The Table Mountain SURFRAD station is located in Colorado and is a mix of exposed rocks, sparse grasses, desert shrubs and small cactus. The Boulder BSRN station, also in Colorado, is very clase to the Table Mountain station and is covered by grass. The Desert Rock SURFRAD station is covered with very sparse vegetation and lies to the northwest of Las Vegas, Nevada. The AmeriFlux site at Howland Forest is located in central Maine, U.S.A., about 35 miles north of Bangor. The natural stands in this boreal-northern hardwood transitional forest consist of hemlock-spruce-fir, and hemlock-hardwood mixtures. The evergreen needle-leaf canopy height at Howland West Tower is about $20 \mathrm{~m}$. The albedo data used here are from 2007 to 2005 , and the albedometer was beated during the winter of 2009 . The Howland Larch Tawer is surroundexl by deciduous needle-Ieaf trees (larch, Larix laricina) (Hollinger, Ollinger, Richardson, Meyers, \& Dail, 2010). The albedo data were collected in 2008 for the Larch Tower. The Ameriflux Harvard Environmental Measurement Station (EMS) tower at Harvard Forest lies in the central Massachusetts town of Petersham. The dominant species include red oak, red mapk, black birch, white pine, and hemlock.

\section{Satelitite albedo}

\subsection{MCD434 standard BRDF/albedo product}

The standard MODIS BRDF/albedo product (MCD43A) (Lucht, Schaaf, \& Strahler, 2000; Schaaf et al., 2002) provides the weighting parameters associated with the RossThick-LiSparse Reciprocal (RTLSR) BRDF model that describes the reflectance anisotropy of each pixel at a $500-\mathrm{m}$ gridded resolution. Both a sufficient number of observations and good angular sampling are needed to achieve a full inversion retrieval and estimate a high quality BRDF. Adknowledged as a trateoff between the temporal stability of the surface reflectance and the availability of sufficient angular samples, a 16-day period of cloud-free, atmospherically-corrected surface reflectances from both Terra (MOD) and Aqua (MYD) is used to derive MCD43A BRDF/albedo (Cao, Schaaf, Strahler, \& Lucht, 2001; Roy. Lewis, Schaaf, Devadiga, \& Boschetti, 2006: Wanner et al., 1997). With an 8 day system of overlapping processing, more phenological variability can be accurately characterized. A backup algorithm (also called a magnitude inversion) is employed if a high quality full irversion retrieval cannot be accomplished due to poor angular sampling or insufficient input observations (Schaaf et al.. 2002). This a priori knowledge method often performs quite well under normal situations (Jin et al, 2003a, 2003b; Liu et al, 2009; Salomon et al, 2006) but should be considered a poor quality result and is assigned a poor quality flag. The MCD43A BRDF/albedo standard product only retrieves a snow albedo quantity when the majocity of observations during a 16 day period are snow-cowered. Snow-covered and non-snow observations are currently always processed separately.

The intrinsic black-sky albedo (BSA) at local solar noon and the white-sky albedo (WSA) is generated by integrating the BRDF calculated from the three retrieved parameters $\left(f_{\text {ison }} f_{\text {geo }}\right.$ and $\left.f_{\text {vol }}\right)$. Btue sky albedo, which considers both the diffuse and direct incident radiation for a specific time and atmospheric state, can be calculated as follows (Lewis \& Barnsley, 1994);

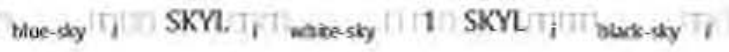

where SKYL (i) is the proportion of diffuse irradiation at a certain solar zenith angle $;$. The SKYL is measured by the shaded pyranometer at the SURFRAD and Howland Forest (West and Larch) sites. Harvard EMS Forest does not have ground SKY data and the MODIS acrosol product (MODO8) is used to calculate the proportion of diffuse irradiation. 

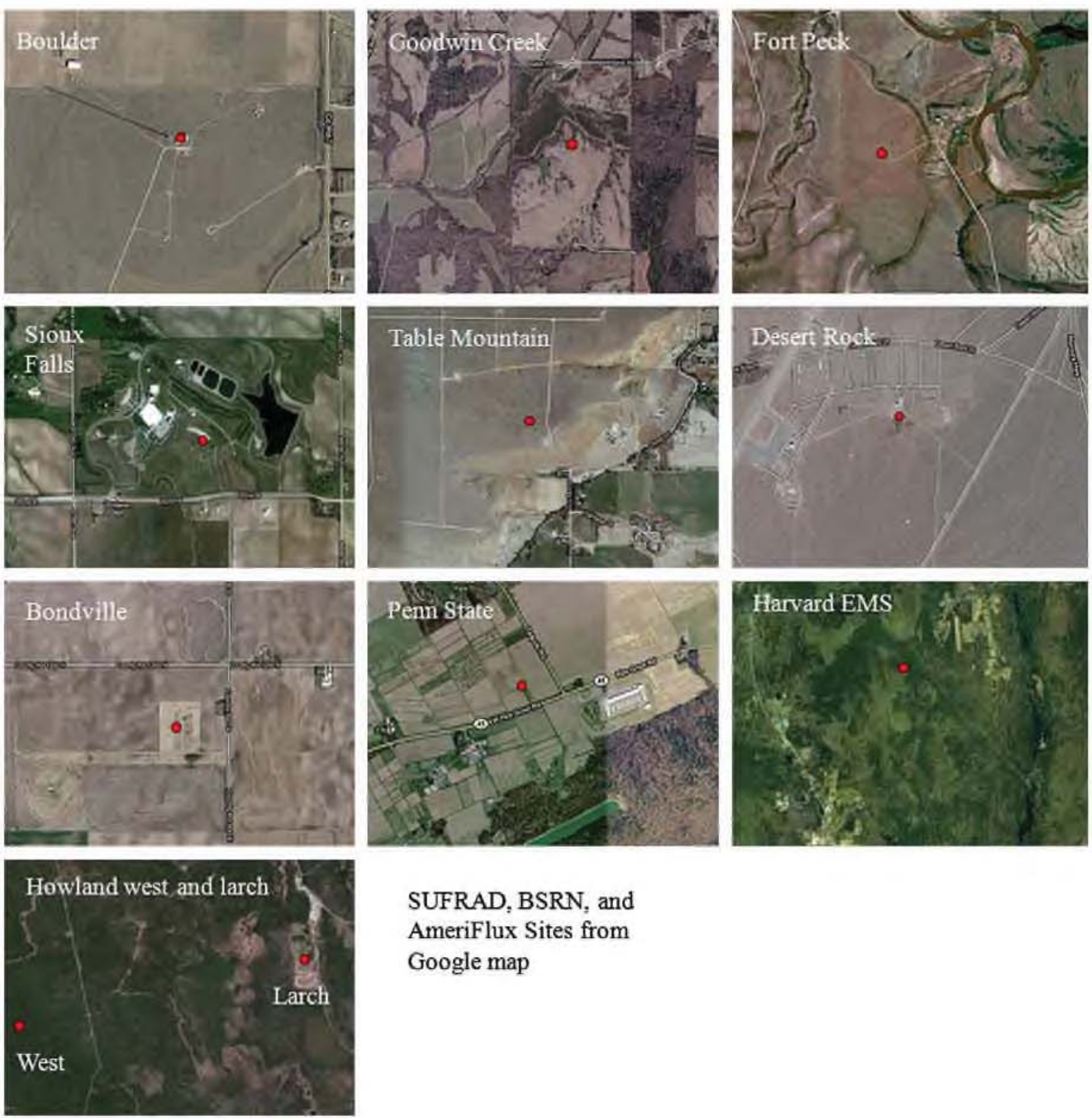
SUFRAD, BSRN, and AmeriFlux Sites from Google map

Fig. 1. The locations of the eleven SUFRAD, BSRN and Ameriflux sites - Boulder, Goodwin Creek, Fort Peck, Sioux Falls, Table Mountain, Desert Rock, Bondville, Penn State, Harvard EMS, Howland West and Howland Larch sites from Google map.

In addition to the spectral quantities, three broadband albedos of VIS $(0.3-0.7 \mathrm{~cm})$, NIR $(0.7-5.0 \mathrm{~cm})$ and shortwave $(0.3-5.0 \mathrm{~cm})$ are calculated from the 7 spectral bands via narrow to broadband conversion coefficients (Liang, Strahler, \& Walthall, 1999; Stroeve et al., 2005).

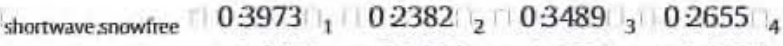

$$
\begin{aligned}
& \begin{array}{l|l|l|l|l|l}
0: 1604 & 00138 & 0 & 00682 & 7 & 00036
\end{array} \\
& \text { shortwavesnow } \left.0: 1574,\left.\quad 0.2789\right|_{2} \mid 03829 /_{3} 0: 1131\right]_{5} \\
& 0106947-010093 \text {; }
\end{aligned}
$$

\subsection{MCD43A direct broadcast (DB) albedo data}

The MODIS DB BRDF/albedo product (Shuai, 2010) which is utilized for regional applications (e.g., forest, agriculture and disturbance monitoring) is operated in a daily rolling mode to provide more frequent surface Nadir BRDF-Adjusted Reflectances (NBAR) and albedos than the current standard product. Two versions of the DB mode are utilized in this study. First, the 16-day daily mode uses 16 days worth of reflectances as input but weights the more recent clear observations (with the highest observation coverage) more heavily. A retrieval is attempted each day based on the proceeding 16 days' worth of data. Full inversions are performed if there are sufficient high quality and well sampled angular observations, where the quality of the angular sampling is determined by reference to the Weights of Determination (Lucht \& Lewis, 2000). Otherwise a magnitude inversion will be processed with the a priori backup database being updated with the most recent full inversion results. Second, the 1-day daily mode, a magnitude inversion is performed each day using the full inversions from the 16-day daily mode as the a priori information for each succeeding day. While this mode emphasizes the single day observation the most heavily, it is also more sensitive to any cloud contamination or residual aerosols affecting that single look. 
